\title{
Dynamic performance evaluation of single bed desiccant dehumidification system
}

\author{
Y. A. F. El-Samadony ${ }^{1}$, A. M. Hamed ${ }^{2,3}$, A. E. Kabeel ${ }^{1}$ \\ ${ }^{1}$ Mechanical Power Engineering Department, Faculty of Engineering, Tanta University, Egypt \\ ${ }^{2}$ Mechanical Engineering Department, Faculty of Engineering, Taif University, KSA \\ ${ }^{3}$ Mechanical Power Department, Faculty of Engineering, Mansoura University, Egypt
}

\section{Email adress:}

samadony25@yahoo.co.uk (Y. A. F. El-Samadony), amhamed1@yahoo.com (A. M. Hamed), kabeel6@hotmail.com (A. E. Kabeel)

\section{To cite this article:}

Y. A. F. El-Samadony, A. M. Hamed, A. E. Kabeel. Dynamic Performance Evaluation of Single Bed Desiccant Dehumidification System, International Journal of Renewable and Sustainable Energy. Vol. 2, No. 1, 2013, pp. 18-25. doi: 10.11648/j.ijrse.20130201.13

\begin{abstract}
In the present work, experimental investigation on the dynamic performance of sealed and less maintenance vertical packed porous bed desiccant dehumidification system has been carried out. The desiccant bed operates as an adsorber and then operates as a regenerator intermittently. In the experimental part of this investigation, silica gel is applied as the desiccant material. Hot air from an air heater is blown through the bed using an air blower in the regeneration process. System performance at different conditions of flowing air is demonstrated. The experimental tests were carried out at different conditions of inlet air and initial bed parameters. Temperature and humidity of air at inlet and exit of the bed were measured. The obtained results show that air with inlet humidity ranging from 5.067 to $10.04 \mathrm{~g} / \mathrm{kg}$ could be dehumidified, using silica gel, to a lower level of humidity $(0.7754 \mathrm{~g} / \mathrm{kg})$. The relation between the studied parameters on the adsorption processes is correlated. Results show that the "Rehabilitation period" in adsorption process could be eliminated if air mass flow rate is greater than $1.92 \mathrm{~kg} / \mathrm{hr}$ per $\mathrm{kg}$ of silica gel.
\end{abstract}

Keywords: Desiccant, Dehumidification, Adsorption, Silica Gel

\section{Introduction}

The dehumidification of air by a desiccant is used both in air-conditioning and industrial applications, particularly when the latent load is large as compared to the sensible load. Desiccant cooling and air dehumidification is a good alternative for the traditional air conditioning system. In the desiccant cooling process, fresh air is dehumidified and then sensibly and evaporatively cooled before being sent to the conditioned space. Since this system works without conventional refrigerants, such as fluorocarbons, and it allows the use of low temperature heat to drive the cooling cycle, it attracted increased attention especially in humid air climate countries. The heat required for regenerating the weak desiccants can be supplied by fossil fuel, waste heat, or any form of low-grade thermal energy, and most of the time, solar energy is used in such processes. Several studies have been conducted on the operation of the desiccant dehumidification employing evaporative cooling processes [1-4].

Solid desiccant cooling and dehumidification systems have received considerable attention in the past several years as alternatives or supplements to conventional vapor compression machines for air conditioning of buildings and spaces that have high latent loads [5]. The research activities in this sector are still increasing to improve the performance and solving the problems that make these systems not yet ready to compete with the conventional air conditioning systems [6 and 7].

Theoretical and experimental study on the transient adsorption characteristics of vertical packed porous bed was carried out by Hamed [8]. He investigated a theoretical model to describe the effect of independent parameters (time, and vertical distance) on the vertical gradient of adsorbable fluid in a desiccant bed.

Hamed et al. [9] studied experimentally the transient adsorption/desorption characteristics of solid desiccant in a vertical fluidized bed. They found that, the relation between the adsorbed water and the moisture fraction for material depends on the thermo-physical properties of the solid adsorbate-adsorbent pair. In silica gel the relation can be expressed as a linear function. They carried out a comparison between packed and fluidized bed adsorption. The test results showed that the performance of the bed under fluidization condition is better than packed one. On 
the other hand, accumulation of the heat of adsorption in packed bed results in increase in the bed temperature when compared with that of fluidized bed.

Kabeel [10] studied the effect of design and operating parameters on the performance of a multilayer desiccant packed bed theoretically and experimentally. He compared his experimental and theoretical results with that of Abd-Elrahman [11], and the results showed reasonable agreement.

Awad et al. [12] attempted to improve the performance of a packed bed dehumidifier. Where, a radial flow hollow cylinder packed bed had been investigated, as they expected, the pressure drop in hollow cylinder bed was too small compared with that in the vertical packed bed. Theoretical investigation of the cyclic operation of the radial flow solid desiccant dehumidifier has been reported [13]. A mathematical model has been developed to predict the effect of air inlet conditions (humidity, temperature and flow rate) as well as bed design parameters on the desiccant bed dynamic performance during cyclic operation. The results show that, lower values of the humidity of process air at bed exit could be attained with increase in regeneration temperature [13].

EL-Samadony et al [14] divided regeneration time of single desiccant bed into four stages and studied the effect of the operating parameters on the global regeneration performance and the divided stages' periods.

In the present study, an experimental unit has been designed and installed to evaluate the effect of design and operating parameters on the dynamic performance of the experimental unit during desiccant dehumidification process stages. Several objectives are formulated to address the overall goal of the present study; evaluation of the effect of design and operating parameters on the performance of single bed desiccant dehumidification system. These objectives are to:

1. Design and installation of a single vertical bed desiccant system coupled with an air heater for regeneration of silica gel in the bed.

2. Study and discuss the operation of the proposed system and evaluate the possibility of steady state operation.

\subsection{Description of the Single Bed Adsorption-Desorption System}

The experimental unit has been designed and installed to evaluate the effect of design and operating parameters on the performance of the experimental unit. A schematic diagram of the single bed adsorption-desorption air dehumidification system is illustrated in figure (1). The system consists of one desiccant bed and three control valves. Silica gel $(95 \%$ White $+5 \%$ Blue, with an average diameter of $3.5 \mathrm{~mm}$ ) is used as desiccant. Bed dimension are $21 \mathrm{~cm}$ diameter and 90 $\mathrm{cm}$ height. The operation schedule of control valves is given in Table (1).
Table 1. the operation schedule of control valves.

\begin{tabular}{lllll}
\hline Case & Valves & $\mathbf{1}$ & $\mathbf{2}$ & $\mathbf{3}$ \\
\hline A & Desorption & Closed & Open & Closed \\
B & Adsorption & Open & Closed & Open \\
\hline
\end{tabular}

\subsection{Experimental Work}

The adsorption and desorption processes were studied for a single bed at different conditions such as air mass flow rate, hot air regeneration temperature and humidity ratio. The system consists of different parts. The blower is used to blow the atmospheric air in the bed. The heater is used to regenerate the desiccant, silica gel, by heating the air. A variac (transformer) is used to change the regeneration air temperature by changing the electrical heater's supplied volt. The of air flow rate to the system is controlled by the valves (see figure $1 \mathrm{~b}, \mathrm{c}$ ) and measured by means of an anemometer which gives the velocity directly in $\mathrm{m} / \mathrm{s}$. Two valves are used to control the amount of air flow rate, valve 1 for adsorption and valve 2 for desoption process. Air inlet and outlet conditions (dry bulb temperature and relative humidity) were measured and recorded by means of a data logger every 10 seconds. The measuring points of air are just before and after Silica gel's bed, as shown in figure (1-A) at points I and II). The humidity ratio of air was calculated by knowing its dry bulb temperature and relative humidity [15].

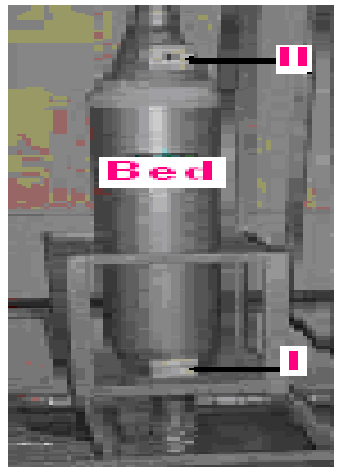

(a)

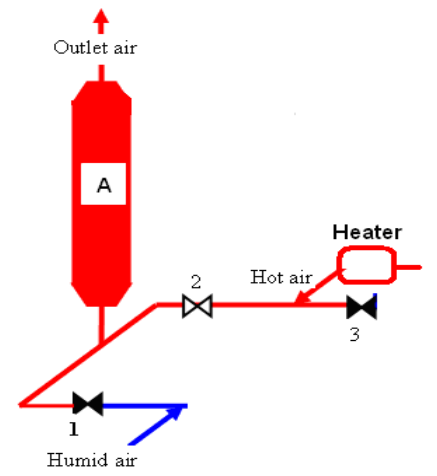

(b)

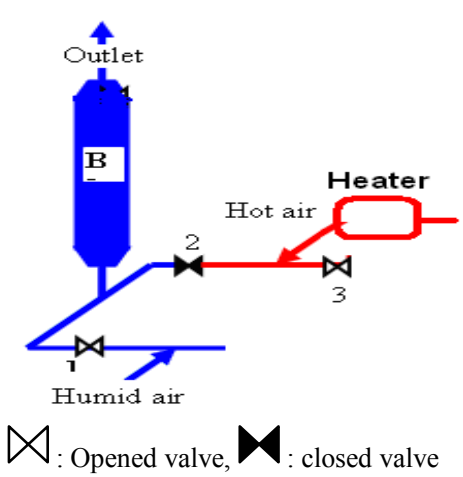

Figure 1. Single bed adsorption-desorption air dehumidification system A: view of the experimental unit, $B$ : desorption mode, $C$ : adsorption mode.

The switching between case A and case B (as shown in 
figure 1) is carried out when the air humidity ratio at outlet is close to that at inlet. At this situation, desiccant bed does not has any ability to adsorb or desorp water vapour. The switching time between case $\mathrm{A}$ and case $\mathrm{B}$ is called adsorption time. To reduce the amount of heat lost from the desiccant bed during the regeneration process, the bed was covered by an insulation jacket.

\section{Results and Discussion}

The performance of desiccant packed bed during adsorption and regeneration processes was evaluated by conducting a series of runs with different inlet conditions of air stream, listed in table (2). This study included the effect of the hot air regeneration temperature and air mass flow rate on regeneration and adsorption time.

Table 2. Air inlet conditions.

\begin{tabular}{lccccccc}
\hline $\begin{array}{l}\text { Inlet air mass } \\
\text { flow rate, } \mathbf{k g} / \mathbf{m i n}\end{array}$ & \multicolumn{5}{c}{$\begin{array}{c}\text { Inlet air } \\
\text { regeneration } \\
\text { temperature, }\end{array}{ }^{\circ} \mathbf{C}$} \\
\hline $\mathrm{Q} 1$ & $\mathrm{Q} 2$ & $\mathrm{Q} 3$ & $\mathrm{Q} 4$ & $\mathrm{~T} 1$ & $\mathrm{~T} 2$ & $\mathrm{~T} 3$ & $\mathrm{~T} 4$ \\
0.58 & 0.64 & 0.71 & 0.77 & 40 & 50 & 66 & 75 \\
\hline
\end{tabular}

\subsection{Adsorption Process}

Figures (2) to (5) illustrate the variation of the outlet to inlet air humidity ratio with the adsorption time for different air mass flow rates and regeneration temperature, which was used in the prior process. It can be seen from these figures that the graphical relationships between outlet to inlet air humidity ratio and adsorption time seemed to be looks like "U" curve i.e. the outlet to inlet air humidity ratio firstly decreases and then increases with time. In the present study, the adsorption process will be divided into four periods; namely "Rehabilitation period", ascending period, uppermost period and descending period, as shown in figure (6).

During the "Rehabilitation period", the ratio of the outlet to inlet air humidity ratio is greater than one. Consequently, an opposite process, regeneration process, will be occurred. In the third period, ascending period, the rate of adsorption increases with time. The uppermost period is the period at which the rate of adsorption is reached to its maximum value for a given conditions. Finally, the forth period, the descending period, the rate of adsorption decreases. It could be seen from figures (2) to (5) that the value of each period is varied with the regeneration temperature and air mass flow rate. The value of uppermost adsorption rate period may be tends to zero for low regeneration temperature, see figures (1) to (4), and vise versa may be occurred for rehabilitation period.

It can be seen also from Figures (2) to (5) that the outlet air temperature decreases as adsorption time increases. However, the lowest value of outlet air temperature is higher than that for the inlet air. This is because adsorption is an exothermic process i.e. releases heat.

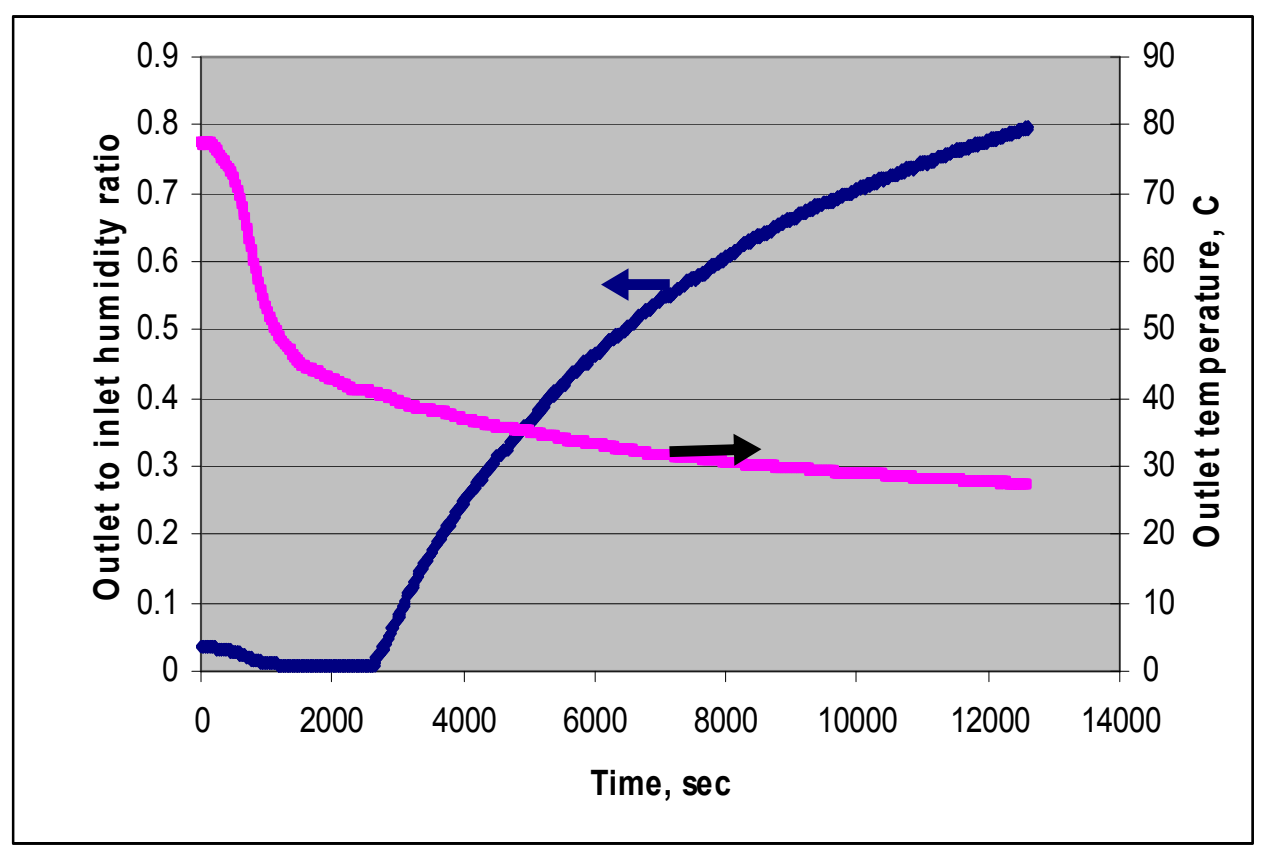

Figure 2. Adsorption process at $T 4$ and $Q 4(W i=7.1 \mathrm{~g} / \mathrm{kg})$. 


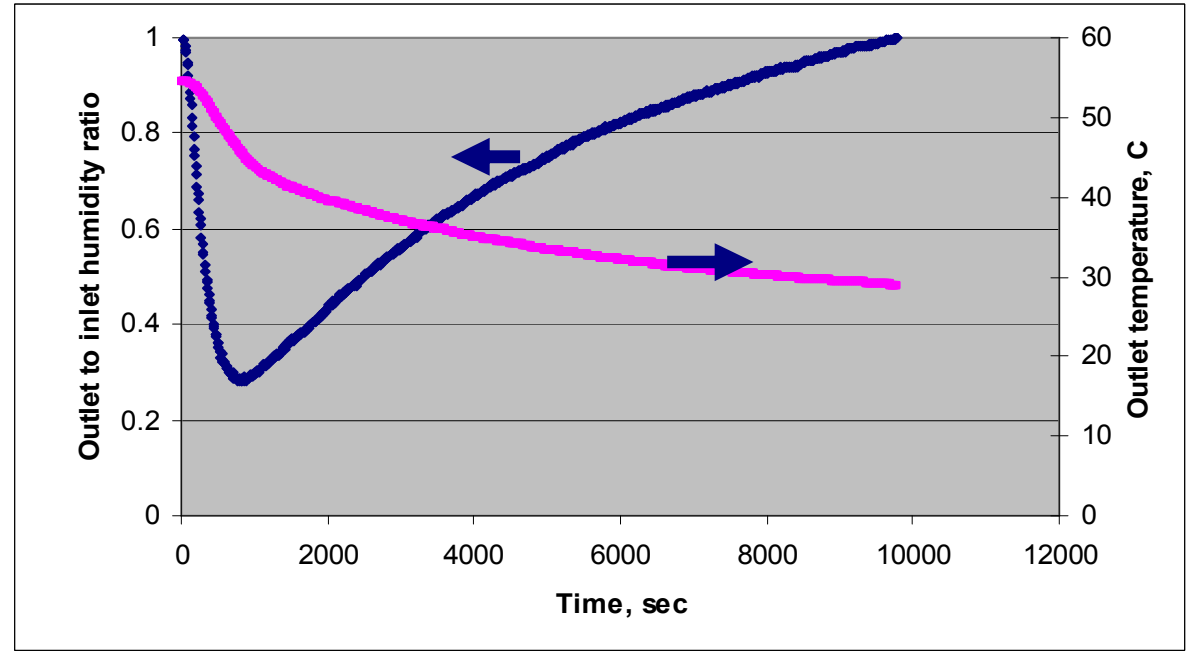

Figure 3. Adsorption process at T3 and $Q 4(W i=7.02 \mathrm{~g} / \mathrm{kg})$.

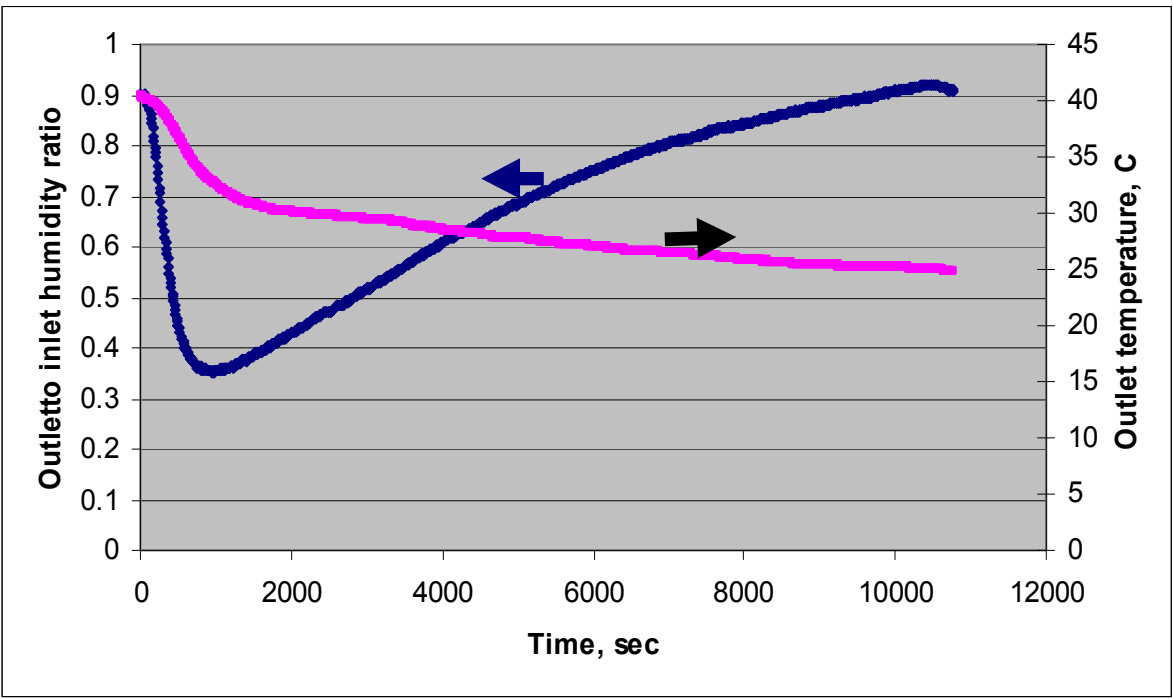

Figure 4. Adsorption process at T2 and $Q 4$. (Wi $=5.117 \mathrm{~g} / \mathrm{kg})$.

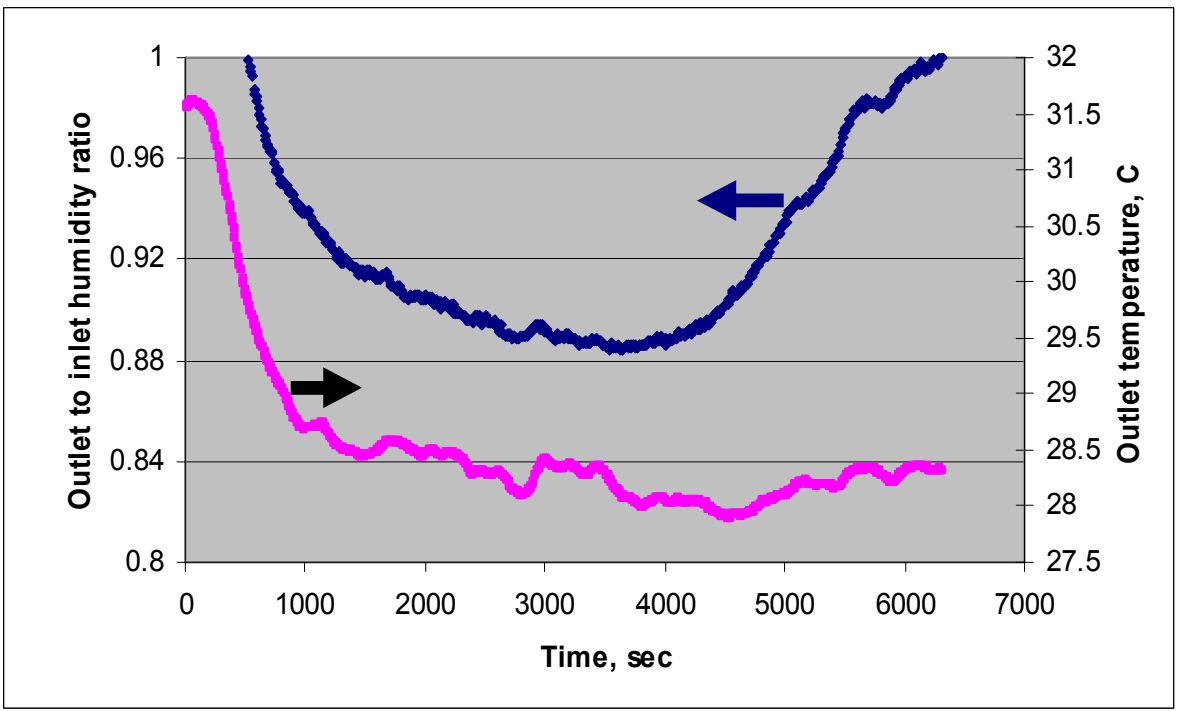

Figure 5. Adsorption process at $T 1$ and $Q 4(W i=8.02 \mathrm{~g} / \mathrm{kg})$. 


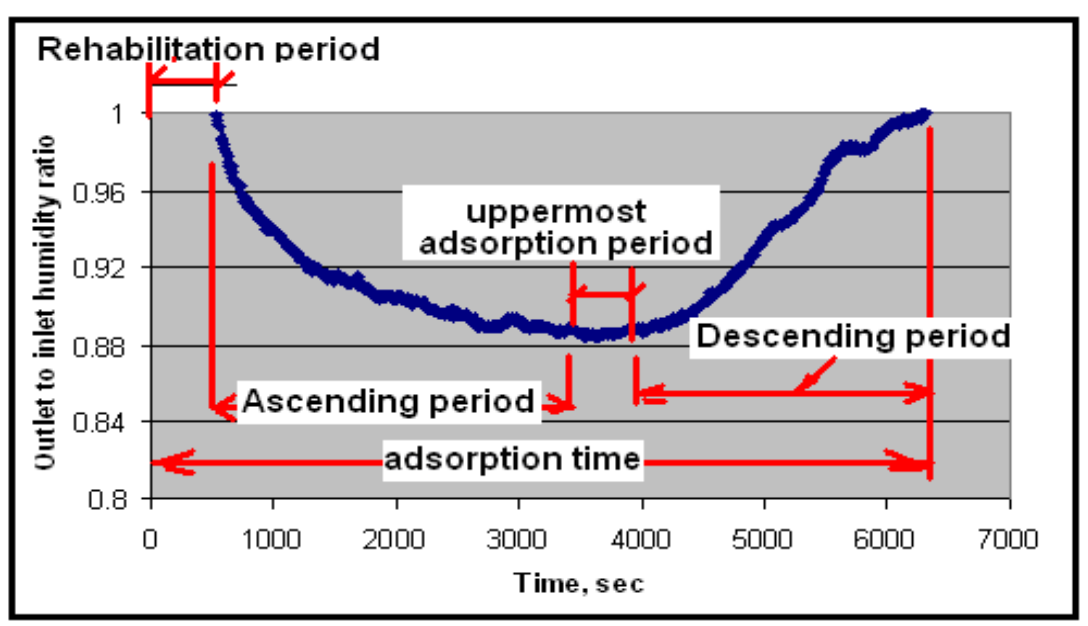

Figure 6. Adsorption process parts, at T1 and Q4.

\subsection{Effect of Air Mass Flow Rate}

Figures (7) to (10) illustrate the variation of the outlet to inlet air humidity ratio with the adsorption time for different air mass flow rate and at a different regeneration temperature. It can be seen, from these Figures that the ascending adsorption rate period decreases as the amount of air mass flow rate increases. This is because as amount of air mass flow rate increases air heat capacity increases and hence could carry out moisture in a short time. Also, it can be seen, from these Figures that the "Rehabilitation period" decreases as the amount of air mass flow rate increases. This is because as amount of air mass flow rate increases air heat capacity increases and hence could carry out heat in a short time. It could be concluded that "Rehabilitation period" can be eliminated if air mass flow rate and former regeneration temperature are greater than $1.92 \mathrm{~kg} / \mathrm{hr}$ per $\mathrm{kg}$ of silica gel and $500 \mathrm{C}$ respectively.

Moreover, it could be seen from these figures that, as amount of air mass flow rate increases Silica gel bed reach to its adsorption saturation point, adsorption time, shorter. Finally, it can be seen from figure (10) that, at high air regeneration temperature, as amount of air flow rate decreases the uppermost adsorption rate period increases.

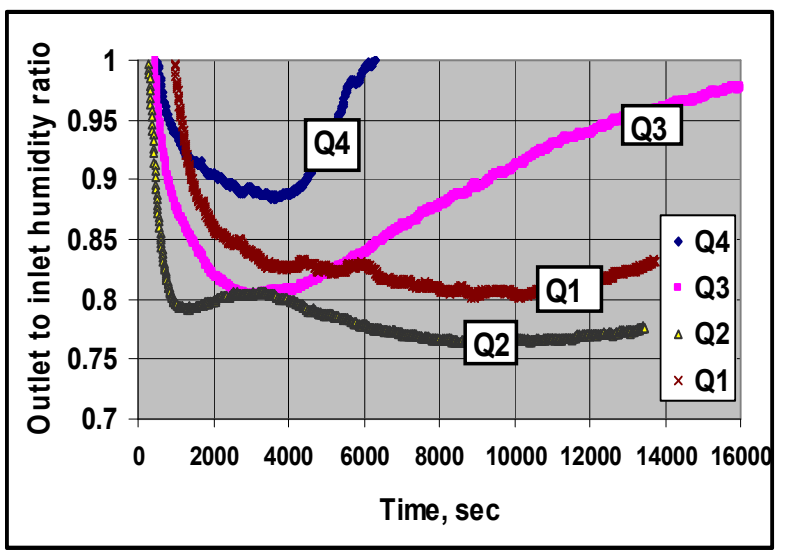

Figure 7. Variation of outlet to inlet humidity with time for different values of flow rate at $T 1$.

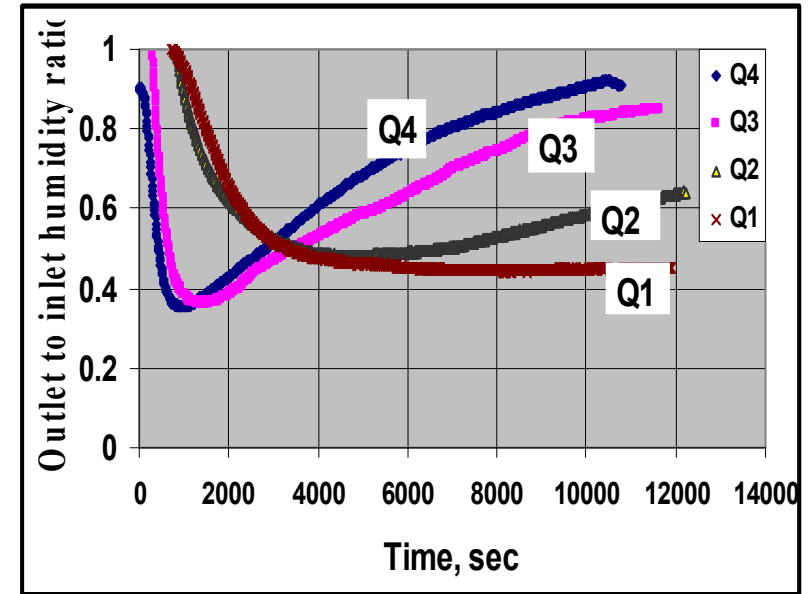

Figure 8. Variation of outlet to inlet humidity with time for different values of flow rate at $T 2$.

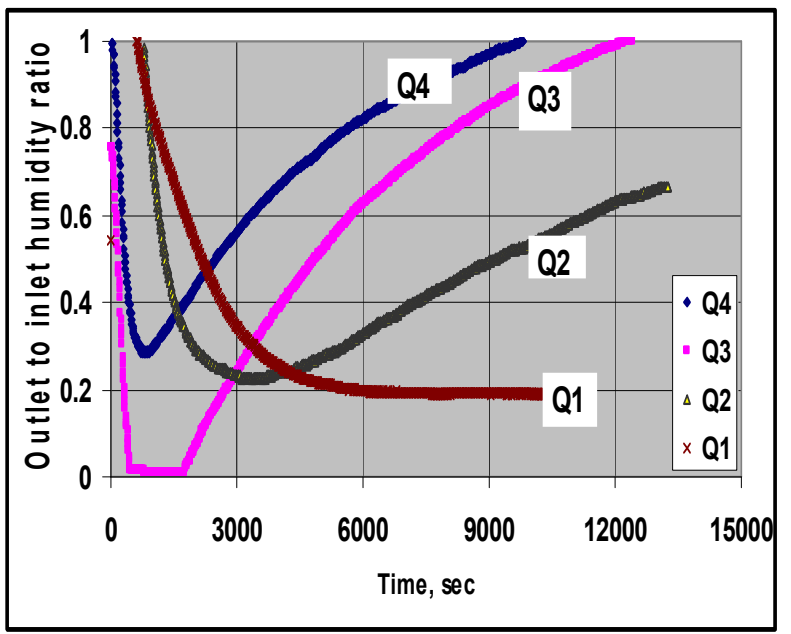

Figure 9. Variation of outlet to inlet humidity with time for different values of flow rate at T3. 


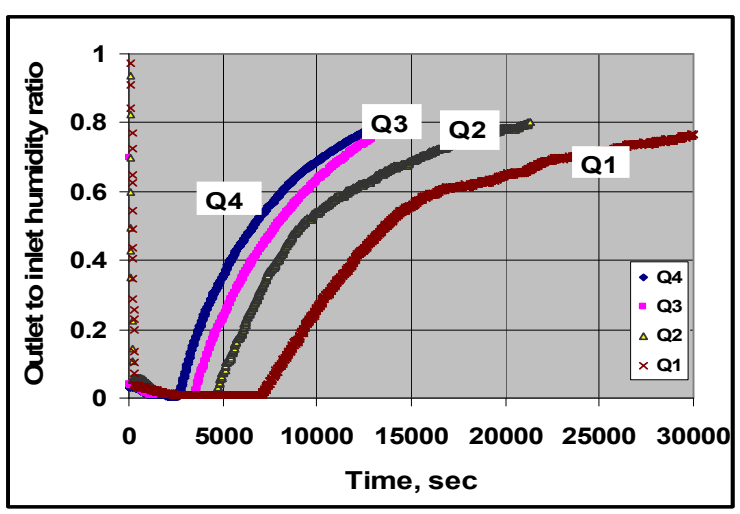

Figure 10. Variation of outlet to inlet humidity with time for different values of flow rate at $T 4$.

\subsection{Effect of Air Regeneration Temperature}

Regeneration temperature has a direct influence on silica gel bed temperature for the following process (adsorption process). Figures (11) to (14) illustrate the variation of the outlet to inlet air humidity ratio with the adsorption time for different regeneration temperature' and at a different air mass flow rate. It can be seen, from these figures that as hot air regeneration temperature, for regeneration process, increases outlet air humidity ratio for the following adsorption process decreases. The value of the outlet to inlet air humidity ratio could be reach to 0.05 and 0.8 for air regeneration temperature of $75{ }^{\circ} \mathrm{C}$ and $40{ }^{\circ} \mathrm{C}$ respectively. Therefore, better adsorption performance is obtained. This is because as the regeneration temperature increases the more water vapour could be released from the Silica gel bed and hence more regenerated Silica gel for the following adsorption process. Consequently, Silica gel adsorbs most of water vapour in the air and the outlet air has very low humidity ratio. Moreover, as the regeneration temperature increases the ability to have uppermost adsorption rate period increases. Finally, it could be seen that, as the regeneration temperature increases the adsorption time increases. This is because the amount of released water vapour from air at high regeneration temperature may three times or more than that released at low regeneration temperature.

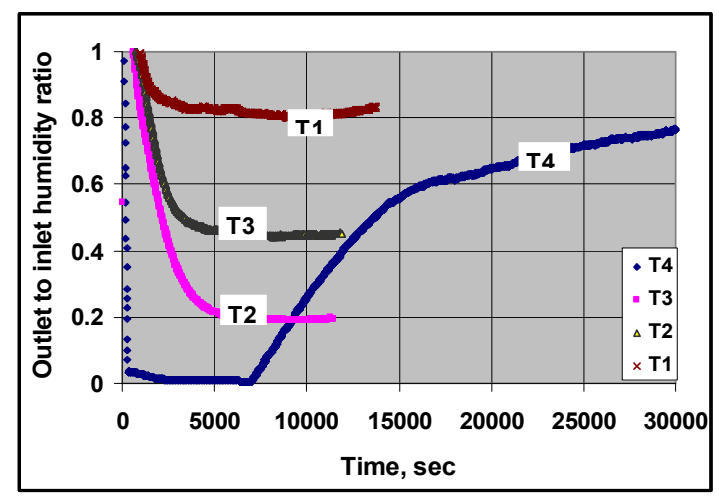

Figure 11. Variation of outlet to inlet humidity with time for different values of regeneration temperature at $Q 1$.

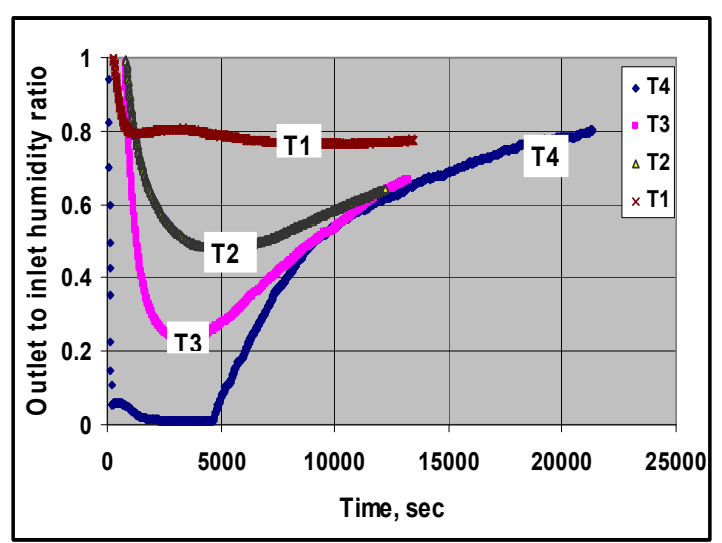

Figure 12. Variation of outlet to inlet humidity with time for different values of regeneration temperature at $Q 2$.

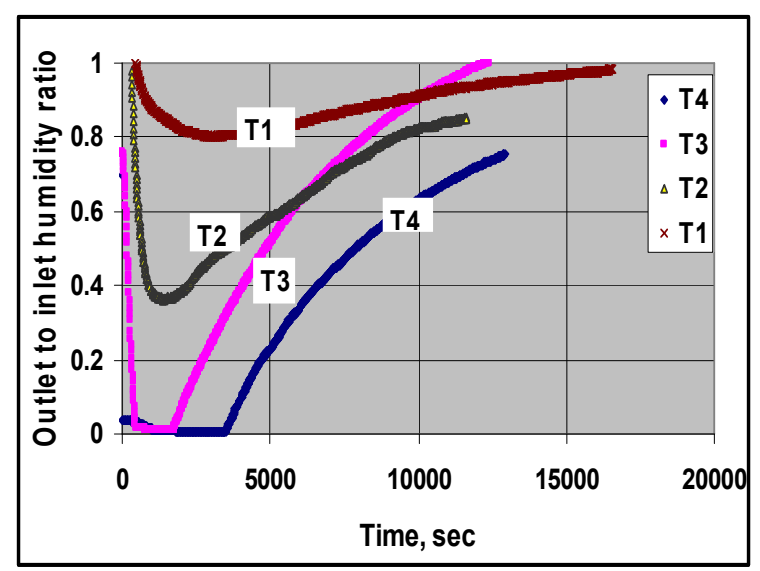

Figure 13. Variation of outlet to inlet humidity with time for different values of regeneration temperature at $Q 3$.

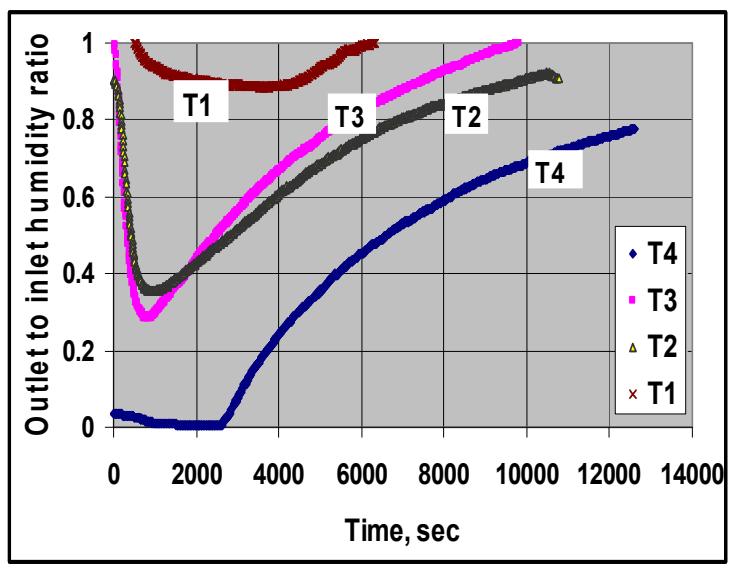

Figure 14. Variation of outlet to inlet humidity with time for different values of regeneration temperature at $Q 4$.

\subsection{Experimental Uncertainty Analysis}

In the present section, the uncertainty analysis of the experimental results is obtained according to [16]. The measurements are done to obtain the following results; air humidity ratio, w, and adsorption/desorption capacity percentage. These results are functioned of two independent variables; dry bulb temperature, $t$, and relative humidity, 
thus

$$
\mathrm{w}=\mathrm{w}(\mathrm{tdb},)
$$

Let $\mathrm{Ww}$ be the uncertainty in the result and $\mathrm{Wt}$ and $\mathrm{W}$, be the uncertainties in the independent variables. The uncertainty in result is calculated according to the equation proposed by [15] as follows:

$$
W_{W}=\left[\left(\frac{\partial w}{\partial T} W_{t}\right)^{2}+\left(\frac{\partial W}{\partial \varphi} W_{\varphi}\right)^{2}\right] \frac{1}{2}
$$

\section{Where}

Uncertainty associated with the measuring dry bulb temperature's $= \pm 0.30 \mathrm{C}$

Uncertainty associated with the measuring relative humidity $=+5 \mathrm{RH} \%$

Calculations show that uncertainties in calculating air humidity ratio and adsorption capacity percentage are $0.33 \%$ and $0.23 \%$ respectively.

\subsection{Experimental Correlation of Air Dehumidification Processes}

The Experimental results (about 21945 data points) are used to obtain a mathematical correlation of outlet to inlet air humidity ratio as a function of time, air mass flow rate and air regeneration temperatures, represented by equation (3). Hopefully, the average error between the actual value, experimental calculated value, of the outlet to inlet air humidity ratio to that obtain from the present correlation is 0.09 . The average error is calculated by calculating the absolute error between the actual experimental value of each outlet to inlet air humidity ratio data and the value that may obtained from the correlation. The average error is the average value of all absolute errors of each data point. Figure (15) represent the deviation between the experimental calculated values of the outlet to inlet air humidity ratio to the corresponding value obtain from the present correlation.

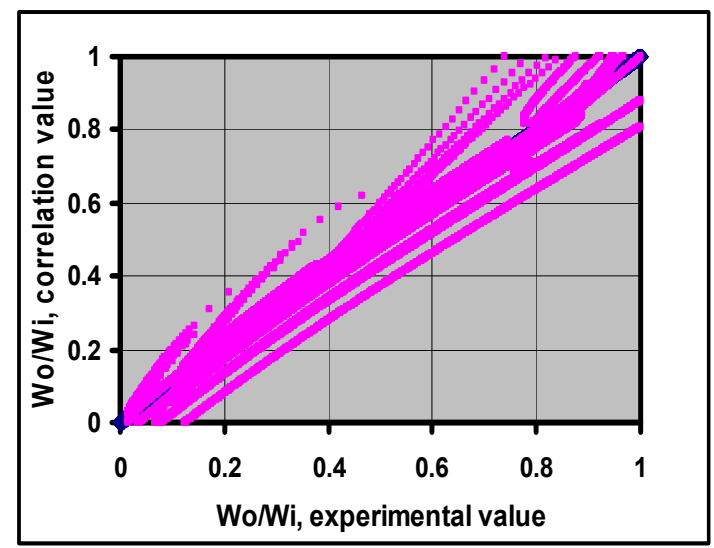

Figure 15. experimental values of the outlet to inlet air humidity ratio to the corresponding value obtain from Eq. (3).

$$
\begin{aligned}
& \frac{w_{o}}{w_{i}}=(C 1)+(C 2)\left(\frac{1}{(\tau / 60)}\right)^{(C 3) \times Q}+ \\
& (C 4)(T)^{(C 5)} \times \tau^{(C 6)}(Q+1)^{(C 7)} \\
& +(C 8)\left(\frac{\tau}{T}\right)^{(C 9) \times Q}+ \\
& (C 10)(T)^{(C 11)}(Q+1)^{(C 12)} \ln \left(\tau^{(C 13)}\right) \\
& +(C 14)\left(\tau^{(C 15)}\right) \\
& +(C 16)\left(Q^{(C 17)}\right)+(C 18)\left(T^{(C 19)}\right)
\end{aligned}
$$

Where

$$
0.00967 \leq \mathrm{Q} \leq .012870,400 \mathrm{C} \leq \mathrm{T} \leq 750 \mathrm{C}
$$

$\mathrm{C} 1=-17.8114, \mathrm{C} 2=7.1264, \mathrm{C} 3=18.9541, \mathrm{C} 4=2207.4280$

$\mathrm{C} 5=-1.9340, \mathrm{C} 6=0.0060, \mathrm{C} 7=78.7616, \mathrm{C} 8=11.8628$

$$
\begin{gathered}
\mathrm{C} 9=6.4506, \mathrm{C} 10=-3.5539, \mathrm{C} 11=-1.5404, \mathrm{C} 12=108.5642 \\
\mathrm{C} 13=15.7229, \mathrm{C} 14=-26.4829, \mathrm{C} 15=-0.8060
\end{gathered}
$$$$
\mathrm{C} 16=-0.16990, \mathrm{C} 17=-3.8731, \mathrm{C} 18=0.5709, \mathrm{C} 19=2.7073
$$

\section{Conclusions}

Desiccant dehumidification system of single bed has been designed, built and tested. A transient adsorption characteristic of silica packed bed has been studied. Experimental results of the instantaneous variation of the air exit parameters (humidity and temperature) are demonstrated. The measurements obtained from the specific tests carried out on desiccant dehumidification system using silica gel as the working desiccant have been analyzed and highlighted. From the analysis, the following conclusions can be drawn.

1. Inlet air temperature in the regeneration (desoption) process has a great influence not only on the regeneration process (as expected) but also on the following adsorption process. Also, results show that the "Rehabilitation period" in adsorption process should be eliminated to decrease the adsorption time.

2. "Rehabilitation period" can be eliminated if air mass flow rate and former regeneration temperature are greater than $1.92 \mathrm{~kg} / \mathrm{hr}$ per kg of silica gel and $500 \mathrm{C}$ respectively.

3. Adsorption time decreases by increasing air mass flow rate and inlet air regeneration temperature in the regeneration (desoption) process.

4. Uppermost adsorption rate period could be achieved at high former regeneration temperature.

5. An acceptable correlation of outlet to inlet air humidity ratio in an adsorption process is obtained with an average error of 0.09 .

\section{References}


[1] W. Pridasawas, Solar-Driven Refrigeration Systems with Focus on the Ejector Cycle, Doctoral Thesis, Stockholm, October 2006.

[2] Waugaman, D.G., Kini, A., Kettleborough, C.F., 1993. A review of desiccant cooling systems. Journal of Energy Resources Technology 115, 1-8.

[3] Mazzei, P., Minichiello, F., Palma, D., 2005. HVAC dehumidification systems for thermal comfort: a critical review. Applied Thermal Engineering 25, 677-707.

[4] Daou, K., Wang, R., Xia, Z., 2006. Desiccant cooling air conditioning: a review. Renewable and Sustainable Energy Reviews 10, 55-77.

[5] Pesaran A. A. and Bingham C. E. (1989) "Testing of Novel Desiccant Materials and Dehumidifier Matrices for Desiccant Cooling Applications," SERI/TP-254-3478.

[6] J. Lee and Dae-Young Lee. (2012)" Sorption characteristics of a novel polymeric desiccant', International journal of refrigeration, 35, PP 1940-1949.

[7] A. Bakhtiar, F. Rokhman, and K. Hwan Choi, (2012)" A novel method to evaluate the performance of liquid desiccant air dehumidifier system, Energy and Buildings 44, 39-44.

[8] Hamed, A. M. (2002) "Theoretical and Experimental Study on the Transient Adsorption Characteristics of a Vertical Packed Porous Bed," Renewable Energy, 27, 525-541.

[9] Hamed. A. M. Abd-elrahman, W. R. and El-Emam, S. H.
(2010) "Experimental study of the transient adsorption/desorption characteristics of silica gel particles in fluidized bed," Energy, 35, 6, 2468-2483.

[10] Kabeel, A. E. (2009) “Adsorption-Desorption Operations of Multilayer Desiccant Packed Bed for Dehumidification Applications," Renewable Energy, 34, 255-265.

[11] Abd-Elrahman, W. R. (2005) "Theoretical and Experimental Study on the Performance of a Fluidized Air Dryer," M.Sc. Thesis. Mechanical Engineering Department, Mansoura University, Egypt.

[12] Awad, M. M., Ramzy A. K. Hamed A. M. and Bekheit M. M. (2008) "Theoretical and Experimental Investigation on the Radial Flow Desiccant Dehumidification Bed," Applied Thermal Engineering, 28, 75-85.

[13] Ramzy A. K., Hamed A. M, Awad, M. M. and Bekheit M. M. (2010) "Theoretical investigation on the cyclic operation of radial flow desiccant bed dehumidifier" Journal of Engineering and Technology Research Vol. 2 (6), pp. 96-110.

[14] Y. A. F. El-Samadony, A M. Hamed, and A E Kabeel (2013)"performance evaluation of single bed desiccant desorption process", Natural Resources, Vol. 3 (1)

[15] ASHRAE Handbook-Applications (1997), American society of heating, ventilation and air conditioning Engineer, 1791 Tullie Circle, Atlanta, GA 30329, USA.

[16] Holman JP, Experimental method for engineers, 6th ed. Singapore: McGraw-Hill; 1994. 